\title{
A Framework to Evaluate the User Experience of Digital Applications using User Centered Design
}

\author{
Arpeet Sahoo \\ Department of Chemical \\ Engineering, \\ Birla Institute of Technology \& \\ Science, Pilani, Rajasthan, India
}

\author{
Arnav Jain \\ Techture Structures Private Limited, \\ Nagpur, India
}

\author{
Remica Aggarwal \\ School of Business, University of \\ Petroleum \& Energy Studies, \\ Dehradun, India
}

\begin{abstract}
Digital applications have become ubiquitous and pervaded all spheres of business and society. This has given rise to the need to measure and evaluate the user experience of such applications. Although, there exist several metrics to measure their effectiveness and efficiency, there is a lack of a framework to guide the design, development and improvement of these applications. This paper is an attempt to design such a framework to improve the user experience of digital applications by implementing the User Centered Design approach.
\end{abstract}

\section{Keywords}

User centered design; user experience metrics; digital applications

\section{INTRODUCTION}

Industry practitioners as well as academics researchers now days describe their experience with technology as User Experience (UX) and often look for ways to broaden their understanding of what constitutes "pleasurable experiences" with technology [1]. User experience is about motivations, attitudes, expectations, behavioral patterns, and constraints. It is about the types of interactions people have, how they feel about an experience, and what actions they expect to take. User experience is a crucial element of digital learning applications. The user experience of a software product is an individual's entire interaction with the product, as well as the thoughts, feelings and perceptions that result from that interaction. With the rapid growth of digital applications in all spheres of daily life, there is a pressing need to focus on the user experience of such applications as they affect us increasingly.

The development and deployment of metrics to measure the user experience is vital. A metric is a way of measuring or evaluating a particular phenomenon or object. User experience metrics are very important to understand the interaction between the learner and the application. They help to ensure the learning objectives are achieved and also to improve upon any shortcomings in the effectiveness of the application. Effectively measuring the usability of any product requires choosing the right metric, applying it, and effectively using the information it reveals.

Different types of user experience metrics are used to measure different aspect of usability. Usually performance metrics are used to measure effectiveness; issue based metrics are used to measure efficiency and self-reported metrics are used to measure satisfaction aspect of usability [2]. But there is a lack of a research in defining a framework of implementation and application of these metrics to holistically develop these applications. This is where the User Centered Design (ISO 9241-210, 2010) comes into the picture.
User-centered design (UCD) is a framework of processes (not restricted to interfaces or technologies) in which the needs, wants, and limitations of end users of a product, service or process are given extensive attention at each stage of the design process. This stages starts from requirements, concepts, pre-production models, mid production and post production creating a circle of proof back to and confirming or modifying the original requirements.

The ISO standard describes 6 key principles that will ensure a design is user centered:

$>$ The design is based upon an explicit understanding of users, tasks and environments.

$>$ Users are involved throughout design and development.

$>$ The design is driven and refined by user-centered evaluation.

$>$ The process is iterative.

$>$ The design addresses the whole user experience.

$>$ The design team includes multidisciplinary skills and perspectives.

These principles define and guide the design process of any product right from the initial stages of identifying the needs or need-finding stage to the post-deployment evaluation stage. We attempt to implement the various principles of the User Centered Design process to a standard digital application design, development and deployment cycle and observe how these principles can drive the entire product design process. The application of User Centered Design principles to digital products and applications are tabulated below.

\section{USER CENTERED DESIGN}

User-centered design (UCD) is a framework of processes (not restricted to interfaces or technologies) in which the needs, wants and limitations of end users of a product, service or process are given extensive attention at each stage of the design process. This stages starts from requirements, concepts, pre-production models, mid-production and post production creating a circle of proof back to and confirming or modifying the original requirements. The ISO standard describes six key principles that will ensure a design is user centered:

$>$ The design is based upon an explicit understanding of users, tasks and environments.

$>$ Users are involved throughout design and development.

$>$ The design is driven and refined by user-centered evaluation. 
$>$ The process is iterative.

$>$ The design addresses the whole user experience.

$>$ The design team includes multidisciplinary skills and perspectives.

These principles define and guide the design process of any product right from the initial stages of identifying the needs or need-finding stage to the post-deployment evaluation stage.

We attempt to implement the various principles of the User Centered Design process to a standard digital application design, development and deployment cycle and observe how these principles can drive the entire product design process. The application of User Centered Design principles to digital products and applications are tabulated below.

Table 1. The application of User Centered Design (UCD) principles to the product design process

\begin{tabular}{|cc|}
\hline UCD Principles & $\begin{array}{c}\text { Application to Product } \\
\text { Design Process }\end{array}$ \\
\hline $\begin{array}{c}\text { P1: Understand the user, the } \\
\text { task and environmental } \\
\text { requirements }\end{array}$ & $\begin{array}{c}\text { Chose appropriate metrics - } \\
\text { apply questionnaires for first } \\
\text { definition [3] }\end{array}$ \\
\hline $\begin{array}{c}\text { P2: Encourage early and } \\
\text { active involvement } \\
\text { of users }\end{array}$ & $\begin{array}{c}\text { Interaction between users and } \\
\text { developers to define the first } \\
\text { version of a prototype [5] }\end{array}$ \\
\hline $\begin{array}{c}\text { P3: Be driven and refined by } \\
\text { user-centered evaluation }\end{array}$ & $\begin{array}{c}\text { Valid evaluation metrics [6] } \\
\text { P4: Include iteration of } \\
\text { design solutions }\end{array}$ \\
$\begin{array}{cc}\text { Continuous interaction } \\
\text { between developers and end- } \\
\text { users in their home } \\
\text { environment leading to several } \\
\text { prototypes [7,8] }\end{array}$ \\
\hline $\begin{array}{c}\text { P5: Address the whole user } \\
\text { experience }\end{array}$ & $\begin{array}{c}\text { Evaluation metrics that covers } \\
\text { all aspects of 'usability', i.e. } \\
\text { effectiveness, efficiency, } \\
\text { satisfaction [7] }\end{array}$ \\
\hline $\begin{array}{c}\text { P6: Encourage multi- } \\
\text { disciplinary design }\end{array}$ & $\begin{array}{c}\text { Team must include members } \\
\text { of varied disciplines }\end{array}$ \\
\hline
\end{tabular}

The stages are illustrated below.

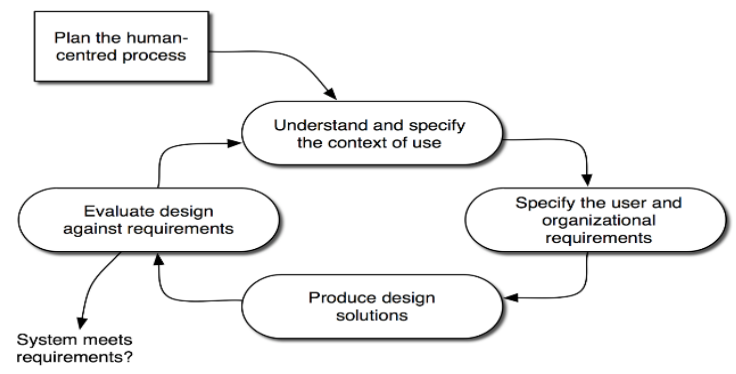

Fig. 1. Stages in the User Centered Design (UCD) process

Adapted from ISO 9241-210 (2008) Ergonomics of human system interaction - Part 210: Human-centered design for interactive systems

Based on the stages of the User Centered Design process, the aspects of a digital product design process are summarized in the below table.
Table 2. Implementing the User Centered Design (UCD) stages to the product design process

\begin{tabular}{|c|c|}
\hline Stages in UCD & $\begin{array}{l}\text { Application to product } \\
\text { design process }\end{array}$ \\
\hline $\begin{array}{l}\text { S1: understand and specify } \\
\text { the context of use }\end{array}$ & $\begin{array}{c}\text { Identified need and potential } \\
\text { impact }[5,8]\end{array}$ \\
\hline $\begin{array}{l}\text { S2: specify the user } \\
\text { requirements }\end{array}$ & $\begin{array}{l}\text { Questionnaires and interviews } \\
\qquad[8,4]\end{array}$ \\
\hline $\begin{array}{l}\text { S3: produce design } \\
\text { solutions to meet user } \\
\text { requirements }\end{array}$ & $\begin{array}{c}\text { Prototypes available for testing } \\
\qquad[5,8]\end{array}$ \\
\hline $\begin{array}{l}\text { S4: evaluate the designs } \\
\text { against requirements }\end{array}$ & $\begin{array}{c}\text { Evaluation metrics } \\
\text { (Effectiveness, Efficiency, } \\
\text { Satisfaction) [9] }\end{array}$ \\
\hline
\end{tabular}

\section{PROPOSED FRAMEWORK}

Thus, applying the User Centered Design process has proved a solid reference point to develop a framework to guide the entire process of planning, designing, developing and later evaluating the user experience of a digital application. The following framework is proposed here to assist in all stages of the development of the user experience of a product .

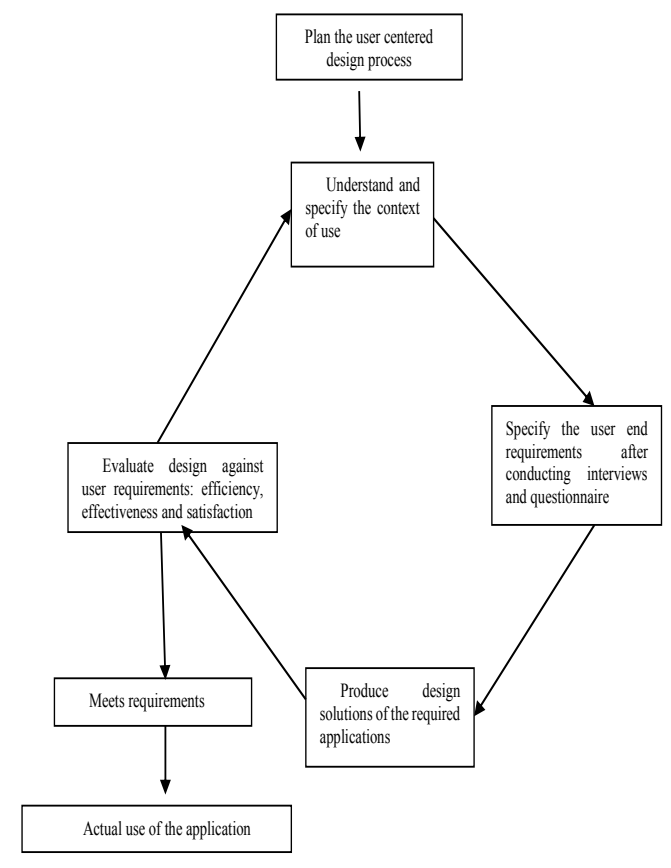

Fig. 1. A framework to develop, measure and improve the user experience based on User-Centered Design (UCD) principles

\section{CONCLUSIONS \& FUTURE DIRECTIONS}

A conceptual framework to measure the user experience with digital applications based on user centered design principles is developed. The framework may be applied with modifications to suit the need of industry other than software industry such as education industry, manufacturing or Architectural , Engineering and Construction (AEC) industry as well. 


\section{ACKNOWLEDGEMENTS}

Authors are thankful to Birla Institute of Technology \& Science for the help and support in conducting this research.

\section{REFERENCES}

[1] Hassenzahl M., Diefenbach S., Göritz A. 2010. Needs, affect, and interactive products - Facets of user experience. Interacting with Computers . 22 (5), 353362.

[2] Tullis, T. and Albert, W. 2013. Measuring the user experience- collecting, analyzing, and presenting usability metrics-Elsevier- Morgan Kaufmann.

[3] Albert, W. Tullis, T. and Tedesco , D. 2010. Beyond the Usability Lab - Conducting Large-scale Online User Experience Studies-Morgan Kaufmann .

[4] Zickler, C., Di Donna, V., Kaiser, V., Al-Khodairy, A., Kleih, S. 2009. BCI applications for people with disabilities: defining user needs and user requirements . In: P.L.Emiliani, L.Burzagli, A Como, F.Gabbanini, Salminen A-L, editors. Assistive Technology from Adapted Equipment to Inclusive Environments, AAATE 25 Assistive Technology Research Series. Amsterdam: IOS Press , 185-189.
[5] Ku" bler, A. Halder, S. and Furdea A, Ho" sle A. 2008. Brain painting: BCI meets art. In: Mu" ller-Putz GR, Brunner C, Leeb R, Pfurtscheller G, Neuper C, editors. 4th International Brain-Computer Interface Workshop and Training Course. Graz, Austria: Technical University of Graz. 361-366.

[6] Zickler, C., Riccio , A, Leotta, F, Hillian-Tress, S. Halder, S. 2011. A brain-computer interface as input channel for a standard assistive technology software. Clin EEG Neurosci , 42 , 236-244.

[7] Zickler, C., Halder, S., Kleih, S.C., Herbert, C., Ku bler, A. 2013. Brain Painting: usability testing according to the user-centered design in end users with severe motor paralysis. Artificial Intelligence Med, 59, 99110

[8] Mu“ nßinger JI, Halder, S., Kleih SC, Furdea A, Raco, V. 2010. Brain Painting: First evaluation of a new brainbomputer interface application with ALS-patients and healthy volunteers. Front Neuroscience . 4.

[9] Holz EM, Zickler C, Riccio A, Ho“ hne J, Cincotti F. 2013. Evaluation of Four Different BCI Prototypes by Severely Motor-Restricted End-Users. 5th International BCI Meeting . Asilomar, Pacific Grove, CA. 